\title{
Analysis of Consecutive Open Surgeries for Varicose Vein at Dhulikhel Hospital.
}

\section{Karmacharya RM, Shakya YR, Shrestha B}

\author{
Department of Surgery \\ Dhulikhel Hospital-Kathmandu University Hospital \\ Dhulikhel, Kavre, Nepal
}

\section{Corresponding Author}

Robin Man Karmacharya

Department of Surgery

Dhulikhel Hospital-Kathmandu University Hospital

Dhulikhel, Kavre, Nepal

Email: reachrobin773@hotmail.com

Citation

Karmacharya RM, Shakya YR, Shrestha B. Analysis of Consecutive Open Surgeries for Varicose Vein at Dhulikhel Hospital. Kathmandu Univ Med J 2014;47(3):190-3.

\section{ABSTRACT}

\section{Background}

Varicose veins are prominent dilated veins in the lower limb primarily due to disease in the junction between superficial and deep venous system. Operative treatment of such condition significantly improves quality of life and also demonstrably decreases the potential complications. We present with analysis of fifty one consecutive open surgeries for varicose vein at Dhulikhel Hospital.

\section{Objective}

To analyze consecutive open surgeries for varicose vein in terms of gender, age, presenting complaints, findings and post operative outcomes.

\section{Method}

All the cases posted for open surgeries for varicose vein at Dhulikhel Hospital during September 2012 - July 2013 were included. If great saphenous vein in thigh was more than $3 \mathrm{~mm}$, segmental stripping was done. The collected data was analyzed using SPSS version 13.0.

\section{Result}

There were 51 cases with $47 \%$ male and $53 \%$ female. Mean age was 48.9 years. Prominent dilated vein was the most common presenting complaints. Incompetent saphenofemoral junction was present in $68.6 \%$ cases. Segmental stripping was done in $51 \%$ cases. Mean days of admission was 2.6 days. Mean pain free day was on 3.2 days. In an average, patient were able to walk normally in 4.1 days. Analysis of hospital admission days, ability to walk normally and pain free day attained in between stripping required and stripping not required group showed significant difference with higher values in stripping required group.

\section{Conclusion}

Although conventional stripping surgery has long been performed for varicose vein, this is associated with prolonged hospital admission, prolonged time required for ability to walk normally, and prolonged time taken for pain free status. Hence newer modalities of treatment like radiofrequency ablation is warranted in our setup too.

\section{KEY WORDS}

Saphenofemoral junction, stripping surgery, varicose vein 


\section{INTRODUCTION}

Varicose veins are prominent dilated veins in the lower limb primarily due to disease in the junction between superficial and deep venous system. This condition can be characterized by unsightly appearance of vessels in limb, pain, itchiness, pigmentation and ulceration causing significant distress. Operative treatment of such condition significantly improves quality of life and also demonstrably decreases the potential complications. ${ }^{1,2}$ Newer modalities of treatment for varicose vein such as radiofrequency ablation have just been made available in our country. Until some time back, we had been doing conservative open surgeries involving one or more of saphenofemoral junction (SFJ) ligation or saphenopopliteal junction (SPJ) ligation, segmental stripping, perforator ligation, multiple phlebectomy. We present the analysis of fifty one consecutive open surgeries for varicose vein at Dhulikhel hospital.

\section{METHODS}

All the cases of open surgery for varicose vein at Dhulikhel hospital are included in the analysis. These cases were performed at Dhulikhel hospital during time period of September 2012 - July 2013. For all cases, preoperative Doppler examination and marking of relevant structures were done. Saphenofemoral junction ligation was done in case of incompetent saphenofemoral junction. Saphenopopliteal junction was done in case of incompetence in saphenopopliteal junction. Stripping was done if the long saphenous vein in the thigh was more than $3 \mathrm{~mm}$ in diameter so that the stripper could be negotiated easily. In case if incompetent perforator, perforator ligation was done by making incision directly over the perforator. For phlebectomy sites, sites with prominent vessels were chosen. If patients could walk unassisted for more than six meters, it was considered as ability to walk normally. Also, in patients on only oral analgesics, after waking if Visual Analogue Scale is less than 2, it was considered as pain free status.

Statistical analysis was done in SPSS 13.0 software. Database management was done in Microsoft access. The data were classified into scalar, ordinal and nominal variables. Frequency analysis was performed for scalar and ordinal variables. For nominal variables, descriptive analysis was performed with calculation of mean, standard deviation. Independent sample t-test was performed for comparing affect on surgical methods to ordinal variables such as hospital admission days. The $p$ value of less than 0.05 was considered significant.

\section{RESULTS}

Of the 51 patients, 24 (47\%) were male and 27 (53\%) were female. Mean age was 48.9 years (SD 6.8). Thirty eight patients (74.5\%) had occupation requiring prolonged standing in which they have to stand for more than 6 hours a day, at least 5 days a week (Table 1). Involvement in right side was significantly more than left side. In history, most common complaints was prominent dilated vein (96.1\%) followed by pigmentation (33.3\%), itchiness (19.6\%) and pain $(17.6 \%)$. In $3.9 \%$ of cases, there was presence of venous ulcer, all of them in Gaiter's area. In $88.2 \%$ of cases, great saphenous system was involved while in $11.8 \%$ cases, lesser saphenous system was involved (Table 2). Based on Doppler examination, incompetent saphenofemoral junction was present in $68.6 \%$ of cases and incompetent saphenopopliteal junction was present in $13.7 \%$ of cases. Regarding perforator incompetence, 35.3\% didn't have incompetent perforator. Most commonly affected perforator vein was mid calf followed by above ankle and below knee perforators.

Table 1. Patient characteristics $(\mathrm{N}=\mathbf{5 1})$.

\begin{tabular}{|ll|}
\hline General Parameters & Number (\%) \\
\hline Occupation requiring prolonged standing & \\
\hline Yes & $38(74.5)$ \\
\hline No & $13(25.5)$ \\
\hline Side of involvement & \\
\hline Right & $33(64.7)$ \\
\hline Left & $18(35.3)$ \\
\hline Prominent vein & \\
\hline Present & $49(96.1)$ \\
\hline Absent & $2(3.9)$ \\
\hline Pain & \\
\hline Present & $9(17.6)$ \\
\hline Absent & $42(82.4)$ \\
\hline Itchiness & $2(3.9)$ \\
\hline Present & $49(96.1)$ \\
\hline Absent & $10(19.6)$ \\
\hline Pigmentation & $41(80.4)$ \\
\hline Present & \\
\hline Absent & $173.3)$ \\
\hline Ulceration & \\
\hline Present & \\
\hline Absent & \\
\hline
\end{tabular}

Saphenofemoral junction ligation was done in 35 cases (68.6\%), segmental stripping was done in 26 (51\%) cases. Saphenopopliteal junction ligation was done in 7 cases (13.7\%). Perforator ligation was done in 32 (62.7\%) of cases. In an average 2.06 phlebectomy was required in each case. Mean days of admission was 2.6days. Mean pain free day was on 3.2 days. In an average, patients were able to walk normally in 4.1 days. In three cases (5.9\%) there was postoperative wound infection.

Hospital admission days, days by which patients were able to walk normally and pain free status attaining day were compared in between two groups as group $A$ in which 
stripping was done and group $B$ in which stripping was not required (Table 3 ). In group $A$ patients, hospital admission days was significantly higher ( 3.00 days to 2.28 days $p<0.01$ ) than group B patients. Also group B patients were able to walk normally and had pain free day earlier than the other group $(p<0.01)$.

Table 2. Anatomical characteristics, surgical procedures performed (N=51).

\begin{tabular}{|c|c|}
\hline Clinical parameters & Number (\%) \\
\hline \multicolumn{2}{|l|}{ Vein system involved } \\
\hline Great Saphenous Vein & $45(88.2)$ \\
\hline Lesser Saphenous Vein & $6(11.8)$ \\
\hline \multicolumn{2}{|c|}{ Sapheno femoral junction } \\
\hline Competent & $16(31.4)$ \\
\hline Incompetent & $35(68.6)$ \\
\hline \multicolumn{2}{|c|}{ Sapheno popliteal junction } \\
\hline Competent & $44(86.3)$ \\
\hline Incompetent & $7(13.7)$ \\
\hline \multicolumn{2}{|l|}{ Perforators } \\
\hline All competent & $18(35.3)$ \\
\hline Mid calf & $12(23.5)$ \\
\hline Above ankle & $9(17.6)$ \\
\hline Below knee & $7(13.7)$ \\
\hline Mid thigh & $3(5.9)$ \\
\hline Above knee & 2 (3.9) \\
\hline \multicolumn{2}{|l|}{ SFJ ligation } \\
\hline Done & $35(68.6)$ \\
\hline Not done & $16(31.4)$ \\
\hline \multicolumn{2}{|l|}{ Stripping } \\
\hline Done & $26(51.0)$ \\
\hline Not done & $25(49.0)$ \\
\hline \multicolumn{2}{|l|}{ SPJ ligation } \\
\hline Done & $7(13.7)$ \\
\hline Not done & $44(86.3)$ \\
\hline \multicolumn{2}{|l|}{ Perforator ligation } \\
\hline Done & $32(62.7)$ \\
\hline Not done & $19(37.3)$ \\
\hline
\end{tabular}

Table 3. Analysis of hospital admission days, ability to walk normally and pain free day attained in between group $A$ and group $B$.

\begin{tabular}{l|ccc|}
\hline Surgical outcomes & $\begin{array}{l}\text { Stripping done } \\
\text { (Group A) }\end{array}$ & $\begin{array}{c}\text { Stripping not } \\
\text { required } \\
\text { (Group B) }\end{array}$ & P value \\
$\begin{array}{l}\text { Hospital admission } \\
\text { days (days) }\end{array}$ & $3.00(0.35)$ & $2.28(0.56)$ & $<0.01$ \\
$\begin{array}{l}\text { Ability to walk nor- } \\
\text { mally (days) }\end{array}$ & $5.38(1.23)$ & $2.88(1.06)$ & $<0.01$ \\
$\begin{array}{l}\text { Days after which } \\
\text { pain free status at- } \\
\text { tained (days) }\end{array}$ & $4.15(1.43)$ & $2.36(1.15)$ & $<0.01$ \\
\hline
\end{tabular}

\section{DISCUSSION}

Varicose vein is a major venous problem worldwide with incidence of about 5-30\% in adult population. ${ }^{3}$ Open surgeries has been used for treatment of varicose vein since centuries. The aim of the operation is to ligate and disconnect the great or lesser saphenous vein with the deep veins. Meticulous dissection in the saphenofemoral junction via the inguinal incision with division of tributaries and flush ligation of great saphenous vein in combination with invaginated stripping of the great saphenous vein to just below knee region had been considered as good choice of open surgery for varicose vein. ${ }^{4}$ Segmental stripping along with saphenofemoral junction ligation is considered necessary in case of incompetence of saphenofemoral junction. In case of varicose vein due to only perforator incompetence, this procedure is not required and even considered harmful by followers of CHIVA technique (Conservative Treatment and Haemodynamics in Venous Insufficiency in Outpatient Departments). ${ }^{5}$ In CHIVA technique after specific venous hemodynamic evaluation, if applicable, only selective perforator ligation is done and stripping is deferred. ${ }^{6}$

In our study, the male and female ratio was almost 1:1. This is in sharp contrast to prevalence studies which have shown this disease as more common in female compared to male. This difference can be due to increased health case seeking behavior in male compared to female in Nepal. The prevalence of varicose vein has been estimated to be higher in women with $25-33 \%$ compared to men with $10-20 \% .^{7}$ In a study done at Edinburgh, prevalence however has been found more in men compared to women. ${ }^{8}$

The mean age for operated cases of varicose vein in our study was $48 . .^{9}$ years which is comparable to the study by Garratt et al. in which the mean age was 45.8 years. ${ }^{9}$ The common presenting symptoms in our study are similar to what mentioned in review article by Ombrellino et al. ${ }^{10}$ In our study $74.5 \%$ of cases had history of occupation requiring prolonged standing. This finding is higher compared to the finding by Tabatabaeifar et al. In their study, in $60 \%$ of cases of varicose vein requiring surgery, there was history of prolonged standing, walking and heavy lifting. ${ }^{11}$

In our study, total hospital admission days, pain free day attained and days in which patients were able to walk normally were significantly lesser in patients in which stripping was not required. This can be due to increased chances of postoperative bruises, hematoma, swelling in cases where stripping is performed. Studies comparing stripping vs endovenous treatment have shown similar benefit of endovenous treatment. Rass et al have revealed advantages concerning hemodynamics, recovery and cosmetic outcome of endovenous treatment in comparision to stripping. ${ }^{12}$ In the cases where stripping has been performed, only proximal segment (vein segment in thigh) has been stripped as the distal segment stripping is associated with high chances of saphenous nerve injury. In study by Jaworucka-Kaczorowska et al., the chances of nerve injury in distal stripping is as high as $36 \% .{ }^{13}$ Due to obvious limitations of stripping, newer modalities of surgical treatment like endovenous laser treatment and Radio Frequency Ablation (RFA) has gained much acceptance. ${ }^{14}$ 


\section{CONCLUSION}

Need of surgery for varicose vein without use of stripper might help in better patient comfort. Newer modalities of

\section{REFERENCES}

1. Kurz X, Lamping DL, Kahn SR, et al. Do varicose veins affect quality of life? Results of an international population-based study. J Vasc Surg. 2001; 34:641-8.

2. Smith JJ, Garratt AM, Guest M, et al. Evaluating and improving healthrelated quality of life in patients with varicose veins. $J$ Vasc Surg. 1999;30:710-9.

3. Hemmati H, Baghi I, Talaei Zadeh K, Okhovatpoor N, Kazem Nejad E. Anatomical variations of the saphenofemoral junction in patients with varicose veins. Acta Med Iran. 2012;50:552-5.

4. Wigger P. Surgical therapy of primary varicose veins. Schweiz Med Wochenschr. 1998;128:1781-8.

5. Bellmunt-Montoya S, Escribano JM, Dilme J, Martinez-Zapata MJ. CHIVA method for the treatment of chronic venous insufficiency. Cochrane Database Syst Rev. 2013;7: 3-7.

6. Parés JO, Juan J, Tellez R, Mata A et al. Varicose vein surgery: stripping versus the CHIVA method: a randomized controlled trial. Ann Surg. 2010;251:624-31.

7. Segiet OA, Brzozowa-Zasada M, Piecuch A, Dudek D et. al. Biomolecular mechanisms in varicose veins development. Ann Vasc Surg. 2015;29:377-84.

8. Evans CJ, Fowkes FG, Ruckley CV, Lee AJ. Prevalence of varicose veins and chronic venous insufficiency in men and women in the general population: Edinburgh Vein Study. J Epidemiol Community Health. 1999;5:149-53. treatment like radiofrequency ablation for varicose vein have such advantage. Studies comparing stripping surgery with radiofrequency ablation will help in knowing more details.

9. A M Garratt, L M Macdonald, D A Ruta, I T Russell et. al. Towards measurement of outcome for patients with varicose veins. Qual Health Care. 1993; 2: 5-10.

10. Michael Ombrellino, Lowell S. Kabnick. Varicose vein surgery. Semin Intervent Radiol. 2005; 22: 185-194.

11. Tabatabaeifar S, Frost $P$, Andersen JH, Jensen LD, Thomsen JF, Svendsen SW. Varicose veins in the lower extremities in relation to occupational mechanical exposures: a longitudinal study. Occup Environ Med. 2015 (ahead of print).

12. Rass K, Frings N, Glowacki P, Hamsch C, Gräber S, Vogt T, Tilgen W Comparable effectiveness of endovenous laser ablation and high ligation with stripping of the great saphenousvein: two-year results of a randomized clinical trial (RELACS study). Archdermatol. 2012 ;148:49-58.

13. Jaworucka-Kaczorowska A, Oszkinis G, Huber J, Wiertel-Krawczuk A, Gabor E, Kaczorowski P. Saphenous vein stripping surgical technique and frequency of saphenous nerve injury. Phlebology. 2014 (ahead of print).

14. Puggioni A, Kalra M, Carmo M, Mozes G, Gloviczki P. Endovenous laser therapy and radiofrequency ablation of the great saphenous vein: analysis of early efficacy and complications. J Vasc Surg. 2005;42:48893. 